\title{
Extraction of the Volatile Oils of Dictyopteris membranacea Batters 1902 by Focused Microwave-assisted Hydrodistillation and Supercritical Carbon Dioxide: Empirical Kinetic Modelling Approach, Apparent Solubility and Rate Constants
}

\author{
N. Riad, ${ }^{a}$ N. Bouzidi, ${ }^{a}$ M. R. Zahi, ${ }^{a}$ O. Touafek, ${ }^{a}$ \\ Y. Daghbouche, ${ }^{a}$ L. Piovetti, ${ }^{b}$ and M. El Hattab ${ }^{a *}$ \\ aUniversity Blida 1, Laboratory of Natural Products \\ Chemistry and Biomolecules, Faculty of Sciences, \\ POB 270, Soumaa Road, Blida, Algeria \\ bUniversity of Toulon, CS 6058483041 Toulon Cedex 9 - France
}

doi: https://doi.org/10.15255/CABEQ.2020.1885

Original scientific paper Received: November 8, 2020 Accepted: July 1, 2021

Supercritical carbon dioxide extraction $\left(\mathrm{SCCO}_{2}\right)$ and focused microwave-assisted hydrodistillation (FMAHD) were used comparatively to isolate the volatile oils of the brown alga Dictyopteris membranacea from the crude ether extract. The volatiles fractions were analysed by GC/MS, the major compounds were: dictyopterene A, 6-butyl1,4-cycloheptadiene, 1-undecen-3-one, 1,4-undecadien-3-one, (3-oxoundec-4-enyl) sulphur, tetradecanoic acid, hexadecanoic acid, 3-hexyl-4,5-dithiacycloheptanone, and albicanol. A kinetics study of the extraction of the volatile fractions obtained by the two processes was carried out, an external calibration allowed to quantify the content of the main metabolites. Empirical models were applied to adjust the experimental kinetics values but also to determine the values of apparent solubilities for $\mathrm{SCCO}_{2}$ and the rate constants for FMAHD. The results obtained revealed that the $\mathrm{SCCO}_{2}$ process was characterized by the coexistence of three distinct phases. For FMAHD, the extraction mechanism included two steps.

Keywords:

Dictyopteris membranacea, volatile oil, $\mathrm{SCCO}_{2}, \mathrm{FMAHD}$, modeling, apparent solubility

\section{Introduction}

Volatiles of marine origin have been rarely studied although they could be used as a source of original flavouring agents in food and perfume industries ${ }^{1}$. The genus Dictyopteris is one of the few genera of odoriferous brown seaweeds. Literature reports that the major constituents identified in the essential oils obtained from algae of this genus were C11 hydrocarbons, known as sex pheromones of brown algae ${ }^{2,3}$, sulphur products such as 3-hexyl-4,5-dithiacycloheptanone (D. plagiogramma, D. australis $^{4}$ and $D$. membranacea ${ }^{5}$, and sesquiterpene compounds (D. prolifera and D. undulata $)^{6,7}$. Essential oil (EO) is traditionally obtained by steam distillation according to ISO-9235 (2013) norms. Currently, various methods can be used for the isolation and extraction of volatile oils from plant materials, which mainly include solvent extraction ${ }^{8}$, supercrit-

"Corresponding author: E-mail: elhattabmohamed@gmail.com and/or elhattab@univ-blida.dz ical fluid extraction (SFE) ${ }^{9}$ and liquid-phase microwave-assisted process (MAP) extraction ${ }^{10}$. Extraction with supercritical carbon dioxide $\left(\mathrm{SCCO}_{2}\right)$ is a good alternative method to preserve the native essential oil components ${ }^{11}$. The thermodynamic (equilibrium) solubility of a compound could be determined by two main methods, static and dynamic ${ }^{12}$. It should be noted that $\mathrm{SCCO}_{2}$ under optimum conditions, is usually a saturated (or almost saturated) solution of extract ${ }^{13}$. Therefore, the concentration of saturated solution in equilibrium with extracted plant is called "apparent solubility". It is an important parameter in the extraction kinetics and could be evaluated from the SFE kinetics data. The term "apparent solubility" is used to distinguish from the thermodynamic solubility, realized when the plant material is in contact with $\mathrm{SF} \mathrm{CO}_{2}$ for a long time to reach the equilibrium concentration, thereby, the apparent solubility is a fraction of the thermodynamic solubility in the SFE of many solutes contained in vegetable organisms ${ }^{14}$. Thus, the thermodynamic and apparent solubilities are usually quite identical for seed oils ${ }^{15}$. However, the thermody- 
namic solubility of volatile compounds is, often, higher than their apparent solubilities ${ }^{16,17}$. It should be noted that theoretical models (TM) as well as semi-empirical and empirical (SE-E) models were employed to predict the solubilities of solute in supercritical $\mathrm{CO}_{2}$. The model parameters are evaluated by minimizing the deviation between experimental data and model predictions using the method of least squares for the determination of the absolute average relative deviation (AARD) or the residual sum of squares (RSS). Some common semiempirical models are reported in literature, i.e., Chrastil ${ }^{18}$, Del Valle and Aguilera ${ }^{19}$, Modified Mendez Santiago-Teja ${ }^{20}$, Modified Bartle ${ }^{21}$, Adachi and $\mathrm{Lu}^{23}$, and Gordillo ${ }^{24}$. The microwave-assisted extraction (MAE) technique was developed and applied to the isolation of volatile and bioactive compounds from plant materials ${ }^{25}$. The main advantage of MAE is the reduction of extraction time and organic solvent production. The kinetics of microwave extraction processes have been reported in many research studies, several mathematical models were proposed to describe the kinetic data ${ }^{26,27}$. The described models were developed using Fick's second law of diffusion $^{28}$, the empirical kinetic model fitting such as: First-order kinetic model ${ }^{29}$, second-order rate kinetic $^{30}$, power law ${ }^{31}$, two-site kinetic model ${ }^{32}$, hyperbolic model (Peleg's model) ${ }^{33}$ and Weibull's exponential model $^{34}$. In a previous work $^{35}$, we had reported the determination and the quantification of the chemical composition of the volatile fraction obtained by three extraction techniques from the crude extract of D. membranacea collected off the Mediterranean coast. The present study aimed to investigate the kinetics study and modelling analysis of the extraction of volatile fractions of $D$. membranacea, firstly by supercritical carbon dioxide at two different pressures, and secondly by focused microwave extraction. An external standard quantification was performed to investigate the evolution of the mass percent $v s$ time of the main compounds in the oils obtained during kinetics study of both extraction techniques.

\section{Materials and methods}

\section{Plant material and chemicals}

The plant material was collected off the coasts of Algeria on the east of Tipaza (36 $37^{\circ} 12$ ' NR, $2^{\circ} 39$ ' 00 ' $'$ E). This sample belongs to Phaeophyceae Class, Dictyotales order, Dictyotaceae family, Dictyopteris genus and polypodioides (Stackhouse) Batters species ${ }^{36}$. D. membranacea is considered as the synonym for $D$. polypodioides which is currently the approved name ${ }^{37}$. The alga was air-dried under shade with no other treatment.

\section{Reagents}

Non-stabilized diethyl ether, dichloromethane and ethyl acetate of analytical grade were purchased from Carlo Erba (Val de Reuil, France). Pure standards (1-Undecene, 3-Undecanone, Copaene, Cedrol, Tetradecanoic acid, Hexadecanoic acid, 1,3-Di(2-thienyl)-1-oxoprop-2-ene) used in external quantification were from Sigma-Aldrich (Saint-Quentin Fallavier, France).

\section{Extraction}

\section{Preparation of crude extract}

Extraction in batch mode (static) for one week at room temperature was performed in triplicate using a ratio of mass $(\mathrm{g})$ of dried seaweed to volume of diethyl ether used as extraction solvent $(\mathrm{mL})$ of 0.15 . The solvent was removed using rotary evaporator under reduced pressure leading to an average mass of $3.5 \mathrm{~g}$ of crude extraction, corresponding to a yield of $1.2 \%$.

\section{Preparation of volatile fractions}

The volatile fractions were prepared from the crude extract using two extraction techniques, $\mathrm{SCCO}_{2}$ and FMAHD.

\section{Preparation of volatile fraction by supercritical carbon dioxide}

The supercritical carbon dioxide extraction was performed on a HP 7680A extractor (Hewlett Packard, Les Ulis, France) equipped with a 7-mL stainless steel extraction vessel. About $300 \mathrm{mg}$ of crude extract were mixed with a sufficient amount of 2-mm diameter glass beads, and heated to approximately $40{ }^{\circ} \mathrm{C}$ in a rotavapor set at slow speed, in the aim of obtaining a homogeneous thin layer of crude extract around the glass beads, thus generating a large contact surface with supercritical carbon dioxide. Thereafter, the glass beads coated with extracts were filled into the extractor. The mixture of oil and fluid leaving the extractor were trapped in a cylindrical tube filled with Tenax GC (60/80 Mesh, Interchim, Montluçon, France), the trap was cooled with a stream of carbon dioxide to maintain the trapping temperature of $0{ }^{\circ} \mathrm{C}$. The oil was then extracted twice with $10 \mathrm{~mL}$ of an equivolume solution of dichloromethane/diethyl ether. The extraction temperature was fixed at $40{ }^{\circ} \mathrm{C}$.

Under the optimized extraction conditions, two kinetics studies were carried out at pressures of 91 and 104 bars. 
Preparation of volatile fraction by focused microwave-assisted hydrodistillation

The focused microwave-assisted hydrodistillatin was carried out in a Discover microwave oven manufactured by CEM (Matthews, NC, USA) equipped with a power modulator and an infrared temperature sensor. The algal extract was mixed with a precise water volume and poured into a pyrex tube topped with a Dean-Starck system allowing the recovery of the oil and water mixture. The ratio of algal extract mass/water volume was optimized in preliminary experiments; the best determined value was: $1 \mathrm{mg} \mathrm{mL}^{-1}$. The kinetics study was carried out at a heating power of $120 \mathrm{~W}$ and $180 \mathrm{~W}$.

\section{Modelling and kinetics study of extraction processes by $\mathrm{SCCO}_{2}$ and FMAHD}

The kinetics study of the overall yield $v s$ time was performed for both techniques $\mathrm{SCCO}_{2}$ and FMAHD. Thus, the overall (cumulative) yield was evaluated by adding the mass of volatile oils extracted vs time. The experimental kinetic data were modelled using two semi-empirical models, the power law ${ }^{31}$ (model 1), and the hyperbolic model ${ }^{33}$ (model 2) described previously and given by equations $1-2$, respectively.

$Y=A t^{n} \quad A$ : constant, $n$ : constant indicative

of transport mechanims $(n<1)$

$Y=\frac{Y_{\infty} t}{B+t} \quad Y_{\infty}:$ asymptotic value of the yield

at infinite time, $B$ : constant

$Y$ : overall yield (mg of volatile oil $/ \mathrm{mg}$ crude extract), $t$ : time (min).

\section{Gas chromatography-mass spectrometry (GC/MS)}

The GC/MS analysis was carried out on a gas chromatograph (HP-6890) coupled to a mass spectrometer (HP-5972) detector. A capillary column CP Sil 8 (30 m length, $250 \mu \mathrm{m}$ i.d., $0.25 \mu \mathrm{m}$ film thickness) was used in the separation. The analyses were performed on the electron ionization mode (EI) at $70 \mathrm{eV}$, the mass range $\mathrm{m} / \mathrm{z} \quad 40-550$ and the ion source temperature used were, 280 and $250{ }^{\circ} \mathrm{C}$, respectively. The samples $(1.0 \mu \mathrm{L})$ diluted in ACOEt $(1: 10 / \mathrm{v}: \mathrm{v})$ were injected using the split mode (1:90) at injection temperature of $250{ }^{\circ} \mathrm{C}$. Helium was used as the carrier gas at a flow rate of $1 \mathrm{~mL} \mathrm{~min}^{-1}$. The GC oven was set initially at $90{ }^{\circ} \mathrm{C}$ and held for $3 \mathrm{~min}$, increased to $220{ }^{\circ} \mathrm{C}$ by a linear ramp at
$3{ }^{\circ} \mathrm{C} \mathrm{min}^{-1}$, and held for $10 \mathrm{~min}$. The compounds were identified based on their mass spectra analysis and the following mass spectra database: Wiley $7 \mathrm{~N}$ (Wiley), NBS 75K (HP), and Mass Finder 4. The identification of compounds was completed by comparing their mass spectra with those reported in literature ${ }^{38,39}$.

\section{Quantitative analysis}

The volatile oils extracted versus time for both extraction methods were analysed by GC/MS. The aim was to quantify the major compounds of the volatile oils, and, consequently, to perform a kinetics study of each compound. The quantification was conducted using suitable pure external standards. The choice of standards was based on their chemical similarity with the compounds of interest in the volatile oils. The calibration of the external standard was better suited than the internal standard for the quantification of small quantities, and required a single point measurement for the determination of the response coefficient, given by equation $3^{40}$. The single-point external calibration strategy is easy to process and quite accurate. However, it requires rigorous injection of the same volume of standard solution and sample (volatile oil) solution in the same conditions.

$$
C_{\text {st }}=K_{\text {rep }} A_{\text {st }} \text { and } C_{\text {comp }}=K_{\text {rep }} A_{\text {comp }}=\frac{C_{\text {st }}}{A_{\text {st }}} A_{\text {comp }}
$$

In equation $3, C_{\mathrm{st}}, C_{\text {comp }}, A_{\text {st }}, A_{\text {comp }}$ are respectively, mass concentration, peak area of pure standards, and quantified compounds in volatile oil. The response coefficient $\left(K_{\text {rep }}\right)$ is determined as the slope of the calibration straight-line resulting from the linear regression of the experimental data plot $[C(\mathrm{i})$, $A(i)]$ obtained by injection of a series of known concentration standard solutions.

\section{Results and discussion}

\section{Kinetics study of the extraction of volatile fractions}

As specified previously, the experimental data of the kinetics study of the oil extraction by $\mathrm{SCCO}_{2}$ and FMAHD were modelled using two semi-empirical models described by equations 1 and 2. Therefore, the best-fit values of the model parameters with the experimental data were determined by minimizing the residual square sum (RSS). Since the extraction mechanisms of $\mathrm{SCCO}_{2}$ and FMAHD were quite different, it seemed more convenient to discuss the modelling results for both techniques separately. 


\section{Kinetics study and modelling of $\mathrm{SCCO}_{2}$}

As previously noticed, the kinetics study of oil extraction was carried out at two extraction pressures $\left(91,104\right.$ bars), and two flows of $\mathrm{SCCO}_{2}$, mainly 0.5 and $1.5 \mathrm{~mL} \mathrm{~min}^{-1}$. The overall extraction curves (OEC) obtained by $\mathrm{SCCO}_{2}$ are described first as overall yield ( $Y: \mathrm{mg}$ oil $/ \mathrm{mg}$ crude extract and/or $Y / \%)$ ) vs time (min) $\left(\mathrm{OEC}_{\text {time }}\right)$ in Fig. 1 and 2. The model parameters, shown in Table 1 were obtained from Figs. 1-2, where $Y_{\infty}$ (exp.) is the overall yield at infinite time, obtained for an exhaustive extraction for a sufficiently long time $(t>2.5 \mathrm{~h})$. The RSS values, for fitting both models to kinetic data, were mainly between 0.017 and 0.44 . For the used pressures and flow rates of $\mathrm{SCCO}_{2}$, model 2 seemed to fit well with the experimental data, most notably for the extraction pressure at 91 bars, characterized by low RSS values. The power law (model 1) seemed well characterised with experimental data for kinetic extraction at 91 bars, however, it showed poor fitting to the one obtained at 104 bars. Most likely, model 2 described the extraction mechanism more correctly than model 1 . Likewise, model 2 showed an asymptotic value of the yield at infinite time more correctly, mainly at the flow rate of 1.5 $\mathrm{mL} \min ^{-1}$.

Table 1 - Kinetics and model parameters for SFE

\begin{tabular}{|c|c|c|c|c|c|c|c|c|c|}
\hline \multirow{2}{*}{$\begin{array}{l}\text { Pressure } \\
\text { (bar) }\end{array}$} & \multirow{2}{*}{$\begin{array}{c}\text { Flow } \\
\left(\mathrm{mL} \mathrm{min}^{-1}\right)\end{array}$} & \multicolumn{3}{|c|}{ Model 1} & \multicolumn{3}{|c|}{ Model 2} & \multirow{2}{*}{$Y_{\infty}$ (exp.) } & \multirow{2}{*}{$\frac{Y_{\infty}(\text { exp. })}{Y_{\infty}(\text { model })}$} \\
\hline & & $A$ & $n$ & RSS & B & $Y_{\infty}($ model $)$ & RSS & & \\
\hline \multirow{2}{*}{91} & 0.5 & 0.41 & 0.62 & 0.128 & 61.42 & 10.90 & 0.049 & 6.70 & 0.61 \\
\hline & 1.5 & 1.00 & 0.41 & 0.017 & 22.70 & 7.70 & 0.072 & 6.85 & 0.89 \\
\hline \multirow{2}{*}{104} & 0.5 & 3.5 & 0.49 & 2.158 & 25.03 & 36.61 & 0.425 & 26.21 & 0.72 \\
\hline & 1.5 & 7.92 & 0.30 & 1.286 & 11.60 & 32.10 & 0.446 & 28.55 & 0.89 \\
\hline
\end{tabular}
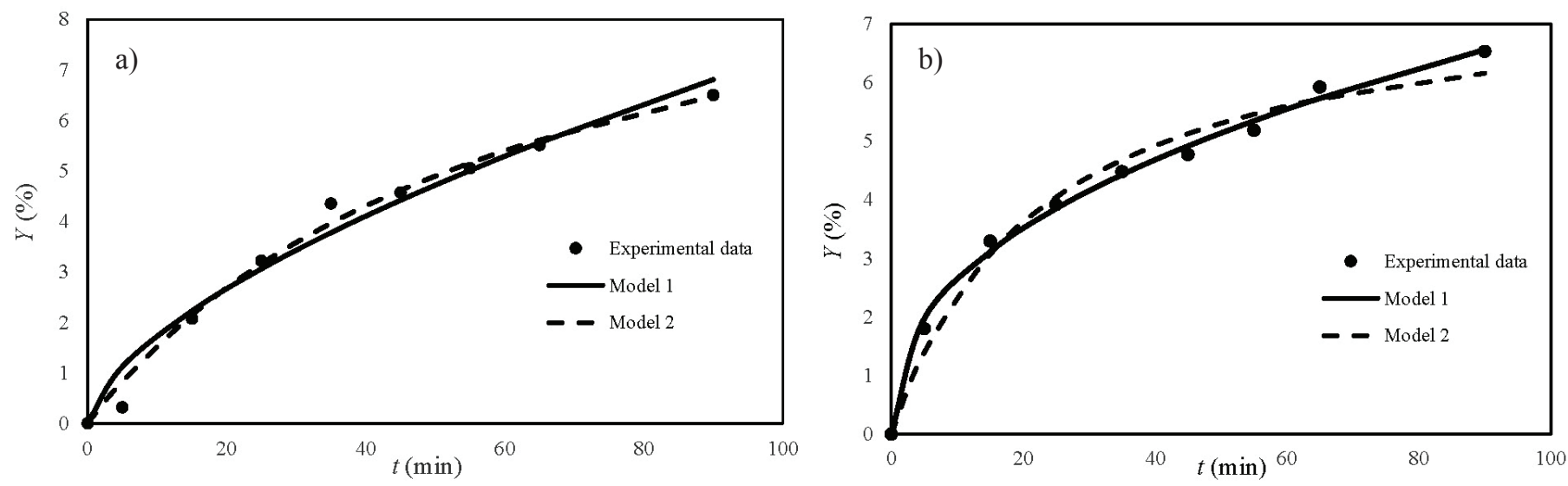

Fig. 1 - Overall extraction curve with SFE at $p=91$ bars (a) $1.5 \mathrm{~mL} \mathrm{~min}^{-1}$, (b) $0.5 \mathrm{~mL} \mathrm{~min}^{-1}$
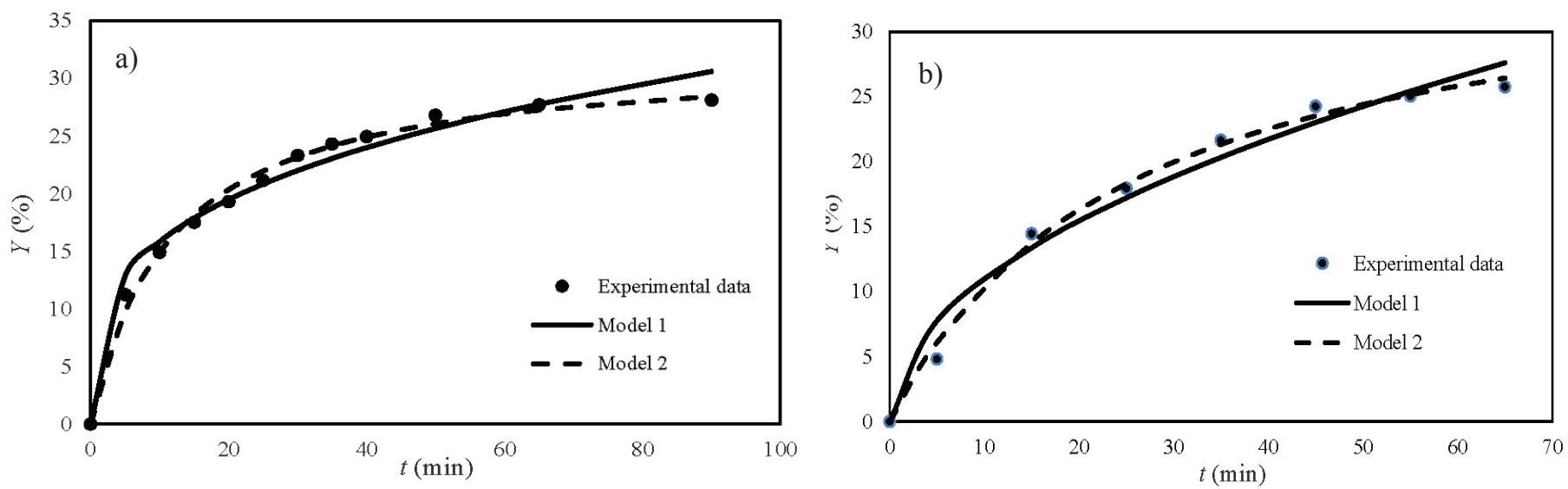

Fig. 2 - Overall extraction curve with SFE at $p=104$ bars (a) $1.5 \mathrm{~mL} \mathrm{~min}^{-1}$, (b) $0.5 \mathrm{~mL} \mathrm{~min}^{-1}$ 


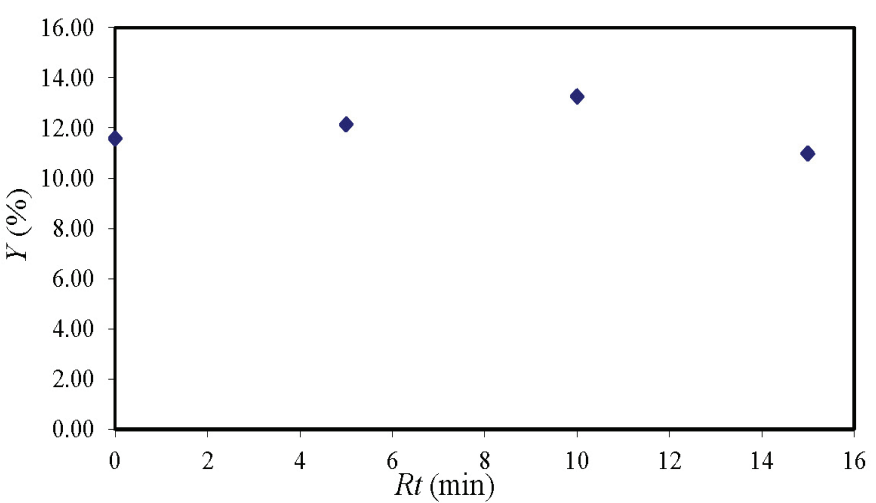

Fig. 3 - Overall yield extraction versus residence time at $p=$ 104 bars

Careful examination of OEC (Fig. 1-2) showed a typical kinetic curve observed for the extraction of natural products characterized by the coexistence of three distinct phases: constant extraction rate period (CER), falling extraction rate period (FER), and diffusion-controlled period (DC), which agreed with the reported literatures ${ }^{41}$.

The first line was identified as the constant extraction rate period (CER), it corresponded to the equilibrium solute concentration in the supercritical carbon dioxide phase, representing the apparent solubility, under specific extraction conditions ${ }^{42}$.

\section{Determination of the apparent solubility}

As reported previously, the mass transfer resistance between the extract and the supercritical carbon dioxide $\left(\mathrm{SCCO}_{2}\right)$ was sufficiently weak, meaning that the concentration equilibrium could be reached relatively quickly, considering the residence (equilibrium) time of $\mathrm{SCCO}_{2}$. This condition was verified by evaluating two extraction runs carried out at different solvent residence times, meaning at different solvent flow rate-to-feed ratios ${ }^{42}$. Thus, the experiment done on the yield variation vs residence time (Rt) (Fig. 3) revealed an almost constant evolution of the yield. This result confirmed that equilibrium was reached nearly instantaneously. We adopted (as recommended in the device manual) a residence time equal to $5 \mathrm{~min}$ for all the experiments. Under these conditions, constant extraction rate period (CER) was used to evaluate the apparent solubility. Thus, OEC was described secondly as overall yield $\left(\mathrm{OEC}_{\mathrm{O} / \mathrm{F}}\right)$ against the solvent-to-feed ratio $q$ (g SCCO $/ 2$ mg crude extract) (Fig. $4-5)$. The
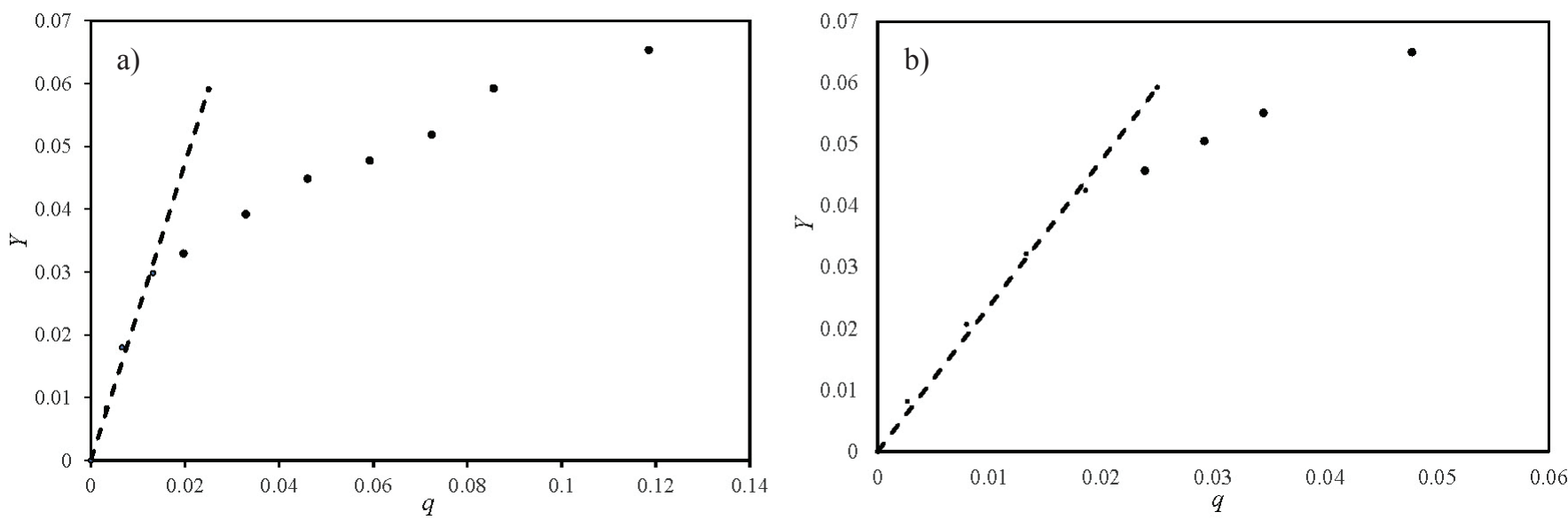

Fig. 4 - Overall yield against the solvent-to-feed ratio $\left(O E C_{O F}\right) q$ at $p=91$ bars and flows (a) $1.5 \mathrm{~mL} \mathrm{~min}^{-1}$ and (b) $0.5 \mathrm{~mL} \mathrm{~min}^{-1}$
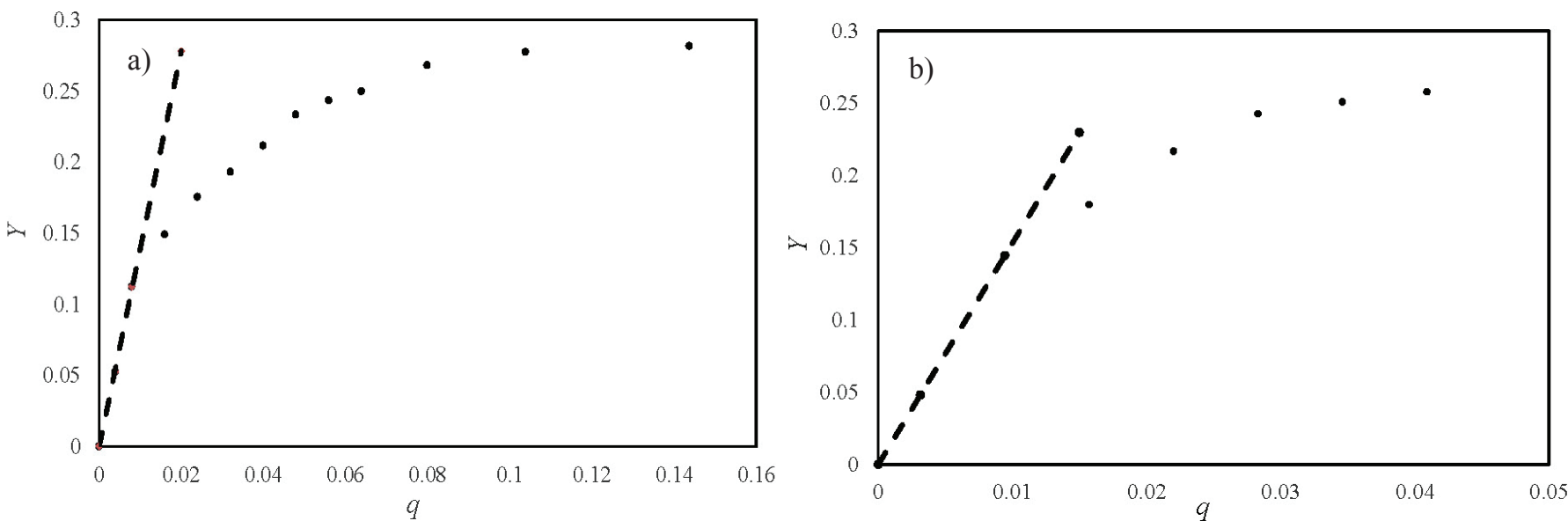

Fig. 5 - Overall yield against the solvent-to-feed ratio $\left(O E C_{O / 1}\right) q$ at $p=104$ bars and flows (a) $1.5 \mathrm{~mL} \mathrm{~min}^{-1}$ and (b) $0.5 \mathrm{~mL} \mathrm{~min}^{-1}$ 
Table 2 - Apparent solubility of volatile oil $\left(\mathrm{mg}\right.$ oil $\left.\mathrm{g}^{-1} \mathrm{SCCO}_{2}\right)$ vs pressure and $\mathrm{SCCO}_{2}$ flow rate

\begin{tabular}{c|c|c}
\hline Pressure (bar) & Flow rate $\left(\mathrm{mL} \mathrm{min}^{-1}\right)$ & Apparent solubility \\
\hline \multirow{2}{*}{91} & 0.5 & 2.37 \\
& 1.5 & 2.36 \\
\multirow{2}{*}{104} & 0.5 & 15.30 \\
& 1.5 & 13.90 \\
\hline
\end{tabular}

Table 3 - Kinetics and model parameters for FMAHD

\begin{tabular}{c|c|c|c|c|c|c|c|c}
\hline \multirow{2}{*}{ Power (W) } & \multicolumn{5}{|c|}{ Model 1 } & \multicolumn{4}{c|}{ Model 2 } & \multirow{2}{*}{$Y_{\infty}$ (exp.) } & $\frac{Y_{\infty}(\text { exp.) }}{Y_{\infty}(\text { model })}$ \\
\cline { 2 - 7 } & $A$ & $n$ & RSS & $B$ & $Y_{\infty}($ model $)$ & RSS & & 0.27 \\
\hline 120 & 0.88 & 0.79 & 0.055 & 0.21 & 28.04 & 0.047 & 7.53 & 0.99 \\
\hline
\end{tabular}

slope of straight line representing the linear interpolation $\left(R^{2}=0.99\right)$ of the first stage of the $\mathrm{OEC}_{\mathrm{O} / \mathrm{F}}$ $(0-10 \mathrm{~min})$ plot defines the apparent solubility, the values obtained are grouped in Table 2 .
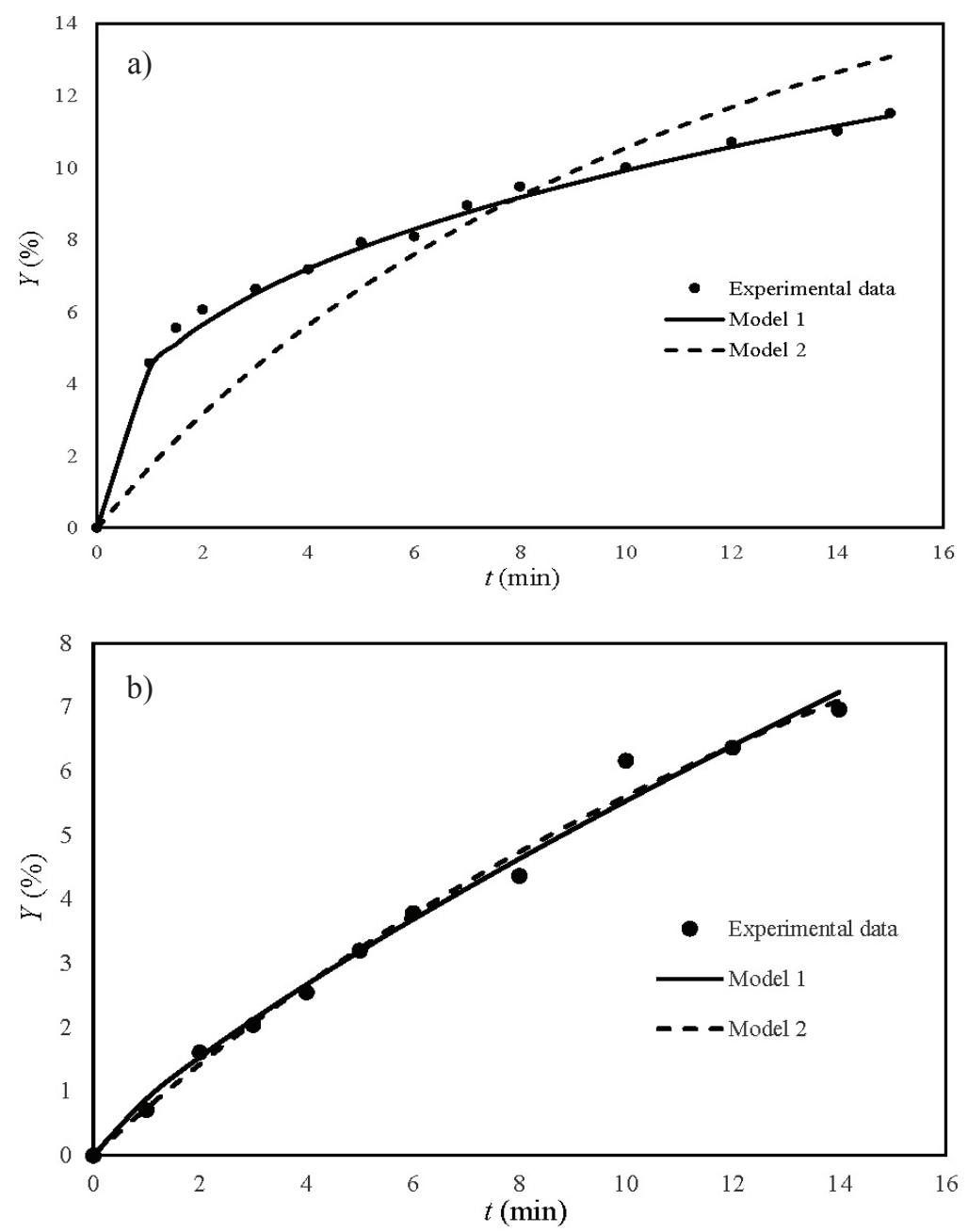

Fig. 6 -Overall extraction curve versus $t$ with FMAHD at (a) $180 \mathrm{~W}$ and (b) $120 \mathrm{~W}$
According to Table 2, the $\mathrm{SCCO}_{2}$ flow had no impact on the apparent solubility values, which were, however, greatly influenced by the pressure. Therefore, the apparent solubility increased about 6 -fold when the pressure had been increased from 91 to 104 bars; this result is hardly surprising because of the close link between pressure and solubility. There are many reports on apparent solubility of extracts $^{43}$, pure compounds ${ }^{44}$ available in literature. However, we found the following values of apparent solubility, at 100 bars of plant volatile oils $\left(\mathrm{mg} \mathrm{g}^{-1}\right)$ : Chamomile $(1.8)^{45}$, Clove $(2.3)^{46}$, Peppermint (5.8) ${ }^{16}$ and St. John's Wort $(4.2)^{17}$. We noticed, from Table 2, that the apparent solubility of alga volatile oil, at 91 bars, was quite similar in comparison to the ones of some terrestrial plants cited previously. This is probably due to a similarity in chemical composition.

\section{Kinetics study and modelling for FMAHD}

The kinetics study was carried out at two heating powers $(120 \mathrm{~W}$ and $180 \mathrm{~W})$, the $\mathrm{OEC}_{\text {time }}$ are shown in Fig. 6. As for $\mathrm{SCCO}_{2}$, the parameters of models 1 and 2 that best fit the experimental kinetic data are given in Table 3.

Analysis of Table 3 suggested clearly that models 1 and 2 gave reasonably the best fit to experimental data, most notably model 2, which showed very good fit to extraction kinetics at $180 \mathrm{~W}$, where RSS and the ratio of asymptotic yield $\left(Y_{\infty}(\exp ) / Y_{\text {(model }}\right)$ tended towards zero and 1, respectively. Analysis of experimental kinetic data (Fig. 6) revealed that the extraction mechanism could be split into two stages (Fig. 7), as reported in the literature $^{47}$ : a fast extraction stage (washing step), 

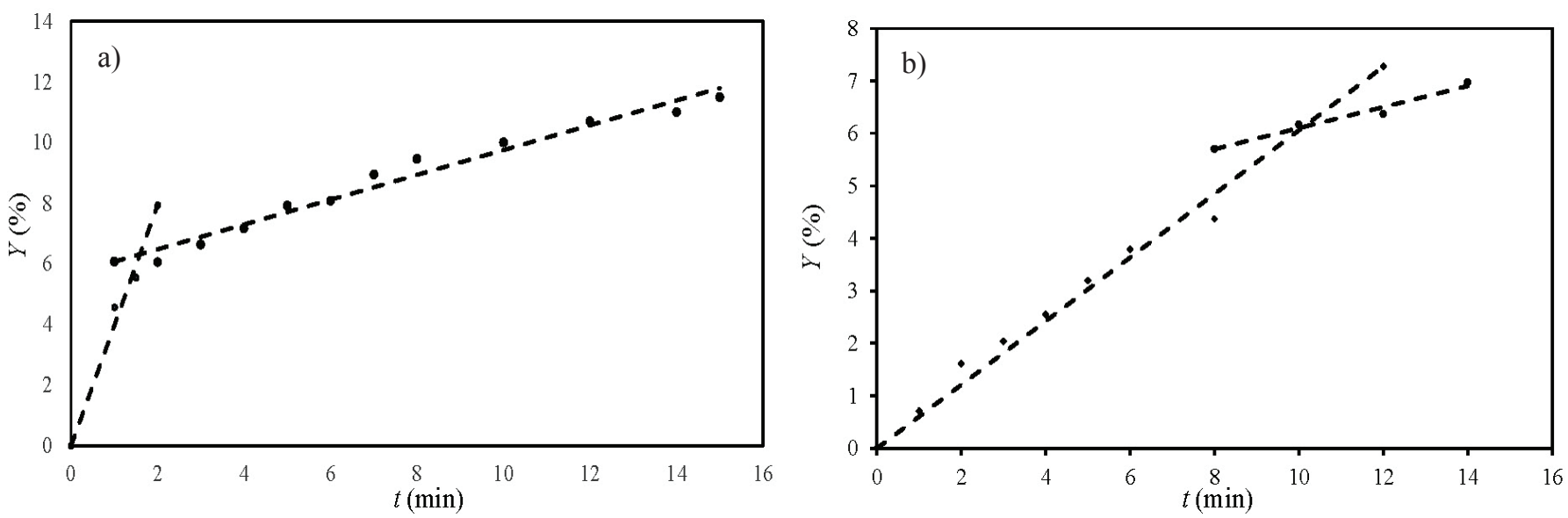

Fig. 7 - Rate constants of FMAHD extraction process at (a) $180 \mathrm{~W}$ and (b) $120 \mathrm{~W}$

Table 4 -Rate constant of washing and diffusion steps for FMAHD at 180 and $120 \mathrm{~W}$

\begin{tabular}{ccc}
\hline Heating power $(\mathrm{W})$ & 120 & 180 \\
\hline Washing step $\left(\mathrm{min}^{-1}\right)$ & 0.61 & 3.97 \\
Diffusion step $\left(\mathrm{min}^{-1}\right)$ & 0.2 & 0.41 \\
\hline
\end{tabular}

and a slow extraction stage (diffusion step). Thus, the OEC at $180 \mathrm{~W}$ (Fig. 7a) revealed the presence of the washing step for a short time, followed by the slow diffusion stage which took more time. Nevertheless, concerning the OEC at $120 \mathrm{~W}$ (Fig. 7b), we noticed the reverse phenomenon, the first stage occurred over a longer time, probably due to the low heating power provoking low volatilization of surface volatile oil. The first step included a washing stage for short time, then the diffusion stage joined the washing stage, both phenomena occurred simultaneously, which explains the relatively long time of the first stage. The second step occurred when the diffusion phenomena became the limiting step of the extraction process. The experimental data of both steps (washing and diffusion steps) could be fitted by linear interpolation, where the slope of the straight could be considered as the extraction rate constant of each step (Table 4).

\section{Modelling and quantitative kinetics study of the main compounds of the volatile oil}

The volatile fractions isolated during $\mathrm{SCCO}_{2}$ and FMAHD kinetics studies were submitted to GC/MS analysis in the aim to carry out a quantitative kinetics study of the main compounds in both oils; the quantification was done as explained previously. The chemical composition of volatile oils obtained by $\mathrm{SCCO}_{2}$ and FMAHD were slightly different. Thus, the $\mathrm{SCCO}_{2}$ oil was characterized by the presence of three chemical classes, previously identified in the essential oils of Dictyopteris genus ${ }^{3-5}$ as C11 hydrocarbons, sulphur compounds, fatty acids and derivatives, as shown in the chromatographic profile (Fig. 8a). In addition, the analysis of the FMAHD oil revealed the presence of the same three chemical classes of components as in $\mathrm{SCCO}_{2}$ oil, and surprisingly, a large amount of sesquiterpenoids (Fig. 8b), the complete identification of both oil compositions is reported in our previous work ${ }^{35}$. The experimental conditions of quantification carried out as described previously are given in Table 5.

Table 5 -Calibration parameters of standards and quantified compounds

\begin{tabular}{|c|c|c|c|}
\hline $\begin{array}{l}\text { Standard compounds; Stock solution } \\
\text { conc. }\left(C \mathrm{mg} \mathrm{mL}^{-1}\right) ; \mathrm{t}_{R}(\mathrm{~min})\end{array}$ & $\begin{array}{l}\text { Response factor } K_{\text {rep }} \\
\text { (mg/unit area) }\end{array}$ & Chemical classes & Compounds quantified and $t_{\mathrm{R}}(\min )$ \\
\hline \multirow[t]{2}{*}{ Undecene; $0.18 ; 6.4$} & $1.14 \cdot 10^{-3}$ & C11 hydrocarbons & Dictyopterene A; 6.7 \\
\hline & & & 6-butyl-1,4-cycloheptadiene; 8.5 \\
\hline \multirow[t]{2}{*}{ Undecanone; $0.22 ; 12.8$} & $2.65 \cdot 10^{-3}$ & Sulphur compounds derivatives & 1-Undecen-3-one ${ }^{(\mathrm{i})} ; 12.1$ \\
\hline & & & 1,4-Undecadien-3-one ${ }^{(\mathrm{ii})} ; 14.1$ \\
\hline Cedrol; $0.19 ; 24.5$ & $1.64 \cdot 10^{-3}$ & Oxygenated sesquiterpenes & Albicanol ; 19.6 \\
\hline Tetradecanoic acid; $0.15 ; 30.1$ & $2.95 \cdot 10^{-3}$ & Fatty acids & Tetradecanoic acid; 30.1 \\
\hline $\begin{array}{l}\text { 1,3-Di(2-thienyl)-1-oxo } \\
\text { prop-2-ene; } 0.16 ; 39.7\end{array}$ & $2.90 \cdot 10^{-3}$ & Sulphur compounds & 3-Hexyl-4,5-dithiacycloheptanone; 34.2 \\
\hline Hexadecanoic acid; $0.15 ; 36.7$ & $4.72 \cdot 10^{-3}$ & Fatty acids and derivatives & Hexadecanoic acid; 36.7 \\
\hline
\end{tabular}

iDerived from (3-oxoundecyl)thioacetate with the loss of a thioacetate group [4].

ii Derived from (3-oxoundec-4-enyl) thioacetate with the loss of a thioacetate group [4]. 


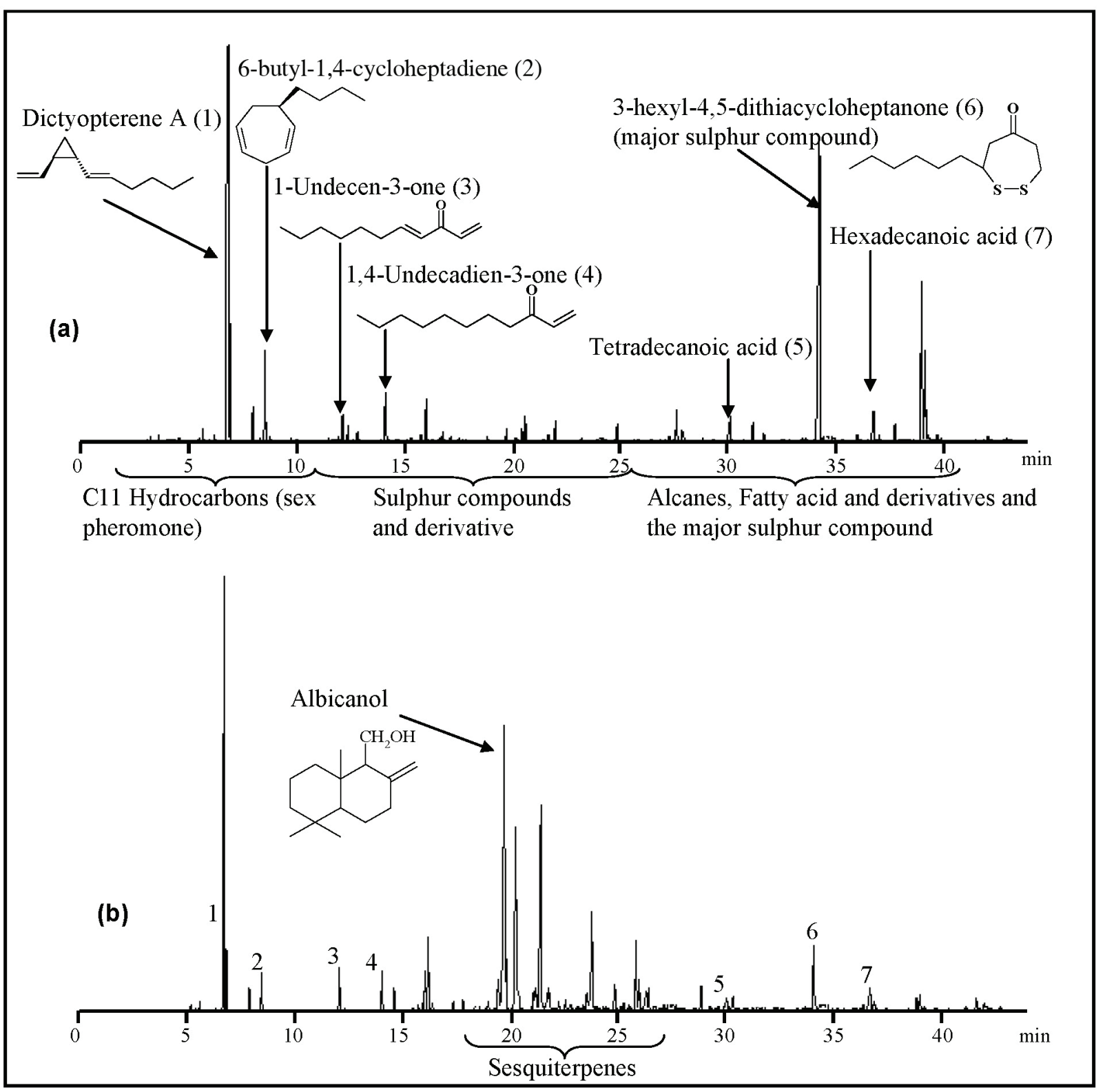

Fig. 8-Chromatographic profiles of the volatile fractions obtained by (a) SFE and (b) FMAHD

The latter includes the concentration of stock solutions, retention times of the standards used, calculated response factor, retention times of the quantified compounds and their chemical classes.

As explained previously and based on the calibration parameters of standards (Table 5), the $\mathrm{OEC}_{\text {time }}$ of the main metabolites were determined for $\mathrm{SCCO}_{2}$ at $p=91$ and 104 bars. The cumulative overall yield was calculated relatively to the mass of the volatile fraction. By way of non-exhaustive illustration, the $\mathrm{OEC}_{\text {time }}$ at 91 and 104 bars of dictyopterene A and 6-butyl-1,4-cycloheptadiene are given in Fig. 9. The OEC of the main metabolites were valorised to deduce graphically their apparent solubility (Table 6) in the same way as for the volatile fraction, e.g., the apparent solubilities of dictyopterene A and 6-butyl-1,4-cycloheptadiene are
Table 6-Apparent solubilities of the main metabolites

\begin{tabular}{l|c|c}
\hline \multirow{2}{*}{ Main quantified metabolites } & \multicolumn{2}{|c}{ Apparent solubility } \\
\cline { 2 - 3 } & $104 \mathrm{bar}$ & $91 \mathrm{bar}$ \\
\hline Dictyopterene A & 4.350 & 1.050 \\
6-Butyl-1,4-cycloheptadiene & 0.271 & 0.060 \\
1-Undecen-3-one & 0.094 & 0.013 \\
$\begin{array}{l}\text { 1,4-Undecadien-3-one } \\
\text { 3-Hexyl-4,5- } \\
\text { dithiacycloheptanone }\end{array}$ & 0.163 & 0.011 \\
Tetradecanoic acid & 3.014 & 0.201 \\
Hexadecanoic acid & 0.140 & 0.014 \\
\hline
\end{tabular}



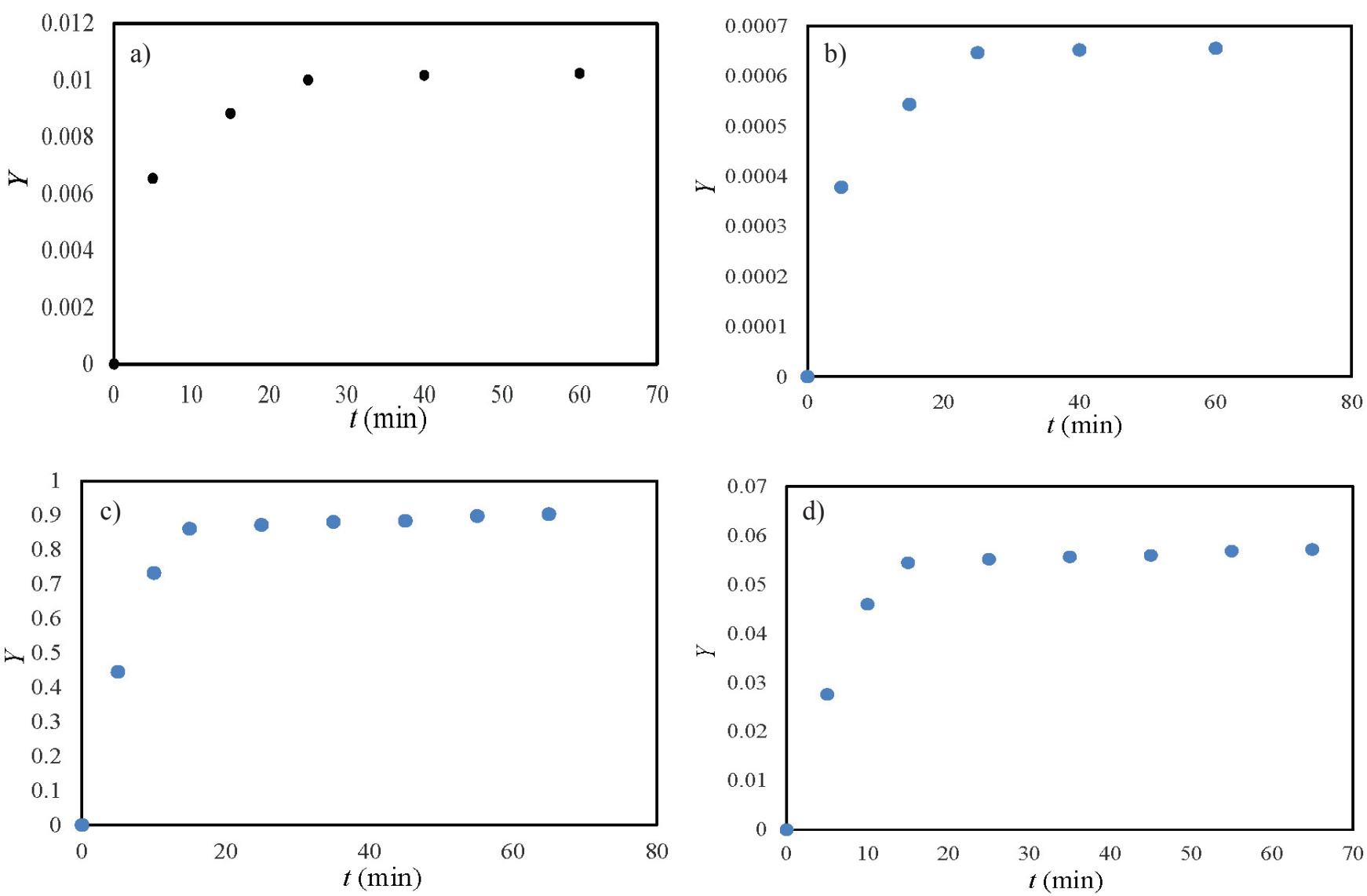

Fig. 9 - Overall extraction curves versus time of dictyopterene A (a, c) and 6-butyl-1,4-cycloheptadiene (b, d) at p = 91 and 104 bars, respectively

illustrated in Fig. 10. The review of apparent solubility data for the main metabolites (Table 6) reveals the increase in dictyopterene $\mathrm{A}$ and 6-butyl-1,4-cycloheptadiene solubilities about 4 times, and between 7 and 14 times for the other metabolites, when the pressure had been increased from 91 to 104 bars. The increases in solubility versus the extraction pressure of extracts and metabolites has been reported in several studies ${ }^{14,48}$, so that the driving force for mass transfer would be larger at high pressure than at low pressure. According to the literature review, the apparent solubilities of natural crude extracts, pure secondary metabolites and pharmaceutical drugs increase between 4 and 10 times by raising the pressure to about 10 bars $^{50,51}$. In the present study, the high increase in apparent solubility of 3-hexyl-4,5-dithiacycloheptanone, tetradecanoic acid and hexadecanoic acid (Table 6) may have been due to their nonpolar character and consequently their high solubility in supercritical carbon dioxide ${ }^{52}$.

In the same context, the volatile fraction extracted by FMAHD was quantified by GC/MS analysis, using the calibration parameters of standard (Table 5), and led to the obtention of $\mathrm{OEC}_{\text {time }}$ of the main metabolites (Fig. 8). The $\mathrm{OEC}_{\text {time }}$ of dic- tyopterene A and albicanol are given in Fig. 11. It is clear that the same phenomenon of extraction process of volatile fraction (Fig. 7), with the intervention of two extraction steps (washing and diffusion), was met in this case as well, and conduct to the measurement of the rate constants of both steps for the main metabolites (Table 7). The review of the results obtained revealed that the rate constants of washing step were higher than were those of diffusion step. However, as regards the four metabolites,

Table 7 -Rate constant of extraction steps of the main metabolites of volatile fraction obtained by FMAHD at $180 \mathrm{~W}$

\begin{tabular}{lcc}
\hline $\begin{array}{c}\text { Rate constant of extraction } \\
\text { process step }\left(\mathrm{min}^{-1}\right)\end{array}$ & Washing step & Diffusion step \\
\hline Dictyopterene A & 0.0295 & 0.0034 \\
1-Undecen-3-one & 0.0148 & 0.0056 \\
1,4-Undecadien-3-one & 0.071 & 0.0434 \\
Albicanol & 0.0306 & 0.0033 \\
$\begin{array}{l}\text { 3-Hexyl-4,5- } \\
\text { dithiacycloheptanone }\end{array}$ & 0.2663 & 0 \\
Tetradecanoic acid & 0.0765 & 0.0263 \\
Hexadecanoic acid & 0.3018 & 0.0919 \\
\hline
\end{tabular}



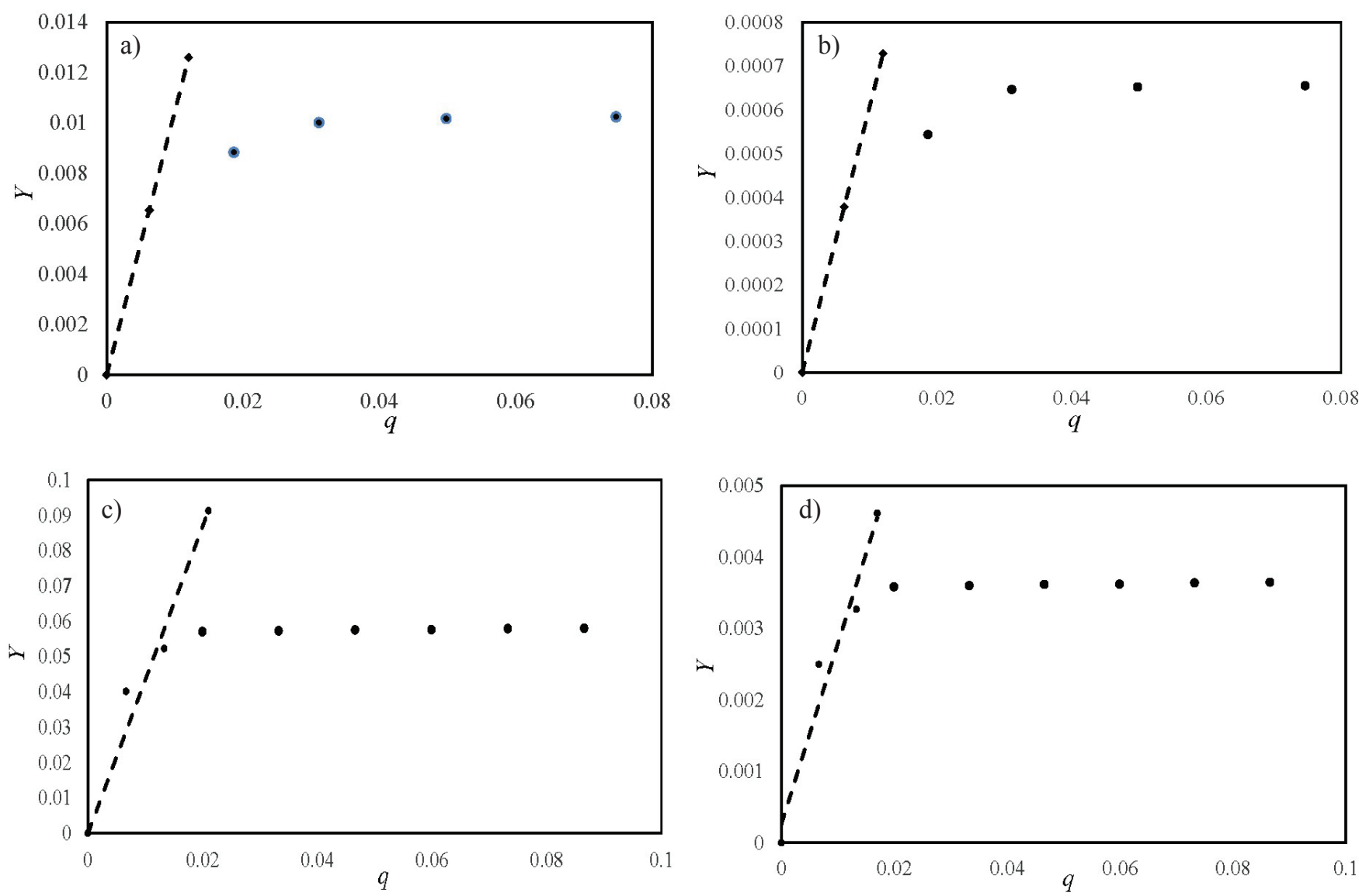

Fig. 10 - Apparent solubility of dictyopterene A (a, c) and 6-butyl-1,4-cycloheptadiene (b, d) at 91 and 104 bars, respectively
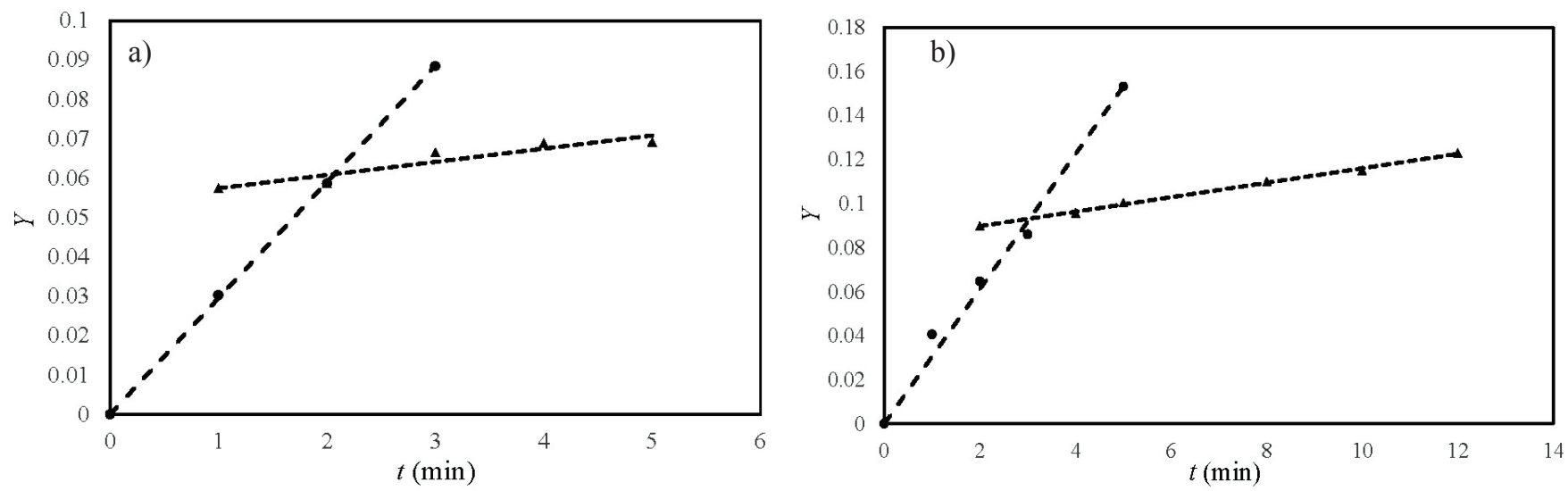

Fig. 11 -Rate constants of dictyopterene A (a), and albicanol (b) obtained with FMAHD at $p=180 \mathrm{~W}$

i.e., 1-undecen-3-one, 1,4-undecadien-3-one, tetradecanoic acid and hexadecanoic acid, the ratio of rate constant of washing and diffusion steps ranged between 1.6 - 3.3. Nevertheless, dictyopterene A and albicanol showed a ratio of 8.6 and 9.3 , respectively. This result could be related to the high volatility of both metabolites, therefore, their easy heteroazeotropic steam distillation. It must be pointed out that the $\mathrm{OEC}_{\text {time }}$ of the main sulphur metabolite, i.e., 3-hexyl-4,5-dithiacycloheptanone, was interpolated by straight line, possibly suggesting that both steps occurred simultaneously, which was probably due to the long-time and low speed taken by the washing step.

\section{Conclusion}

The volatile fractions were prepared from crude ether extract of Dictyopteris membranacea by $\mathrm{SCCO}_{2}$ and FMAHD. The kinetics studies of the volatile fraction extraction were performed and 
conducted to the $\mathrm{OEC}_{\text {time }}$. Two empirical models were used to best-fit the kinetic experimental data, thus leading to the determination to the model's parameters, and then valorised in the determination of apparent solubilities for $\mathrm{SCCO}_{2}$ and the rate constants for FMAHD. The volatile fractions collected during the kinetics studies were submitted to GC/MS analysis associated to an external standard quantification to determine the mass content of the main metabolites in the oils, and consequently the $\mathrm{OEC}_{\text {time }}$ for each metabolite. The $\mathrm{OEC}_{\text {time }}$ was exploited in the determination of the apparent solubilities, and the rate constant of the main metabolites for $\mathrm{SCCO}_{2}$ and FMAHD, respectively.

\section{Nomenclatures:}

$A_{\text {st }}, A_{\text {comp }}-$ Area of standard and quantified compound, respectively (digital units)

$C_{\mathrm{st}}, C_{\text {comp }}-$ Concentration of standard and quantified compound, respectively $\left(\mathrm{mg} \mathrm{mL}^{-1}\right.$ solution)

FMAHD - Focused Microwave-assisted Hydrodistillation

MAP - Microwave-assisted process

$\mathrm{OEC}_{\text {time }}-$ Overall extraction curves: Variation of overall yield in percent versus time

$\mathrm{OEC}_{\mathrm{O} / \mathrm{F}} \quad-$ Overall yield against the solvent-to-feed ratio $q$

$q \quad-$ Feed ratio (g $\mathrm{SCCO}_{2} / \mathrm{mg}$ crude extract)

Rt $\quad-$ Residence time, min

RSS - $\quad$ Residual square sum

$R^{2} \quad-\quad$ Linear coefficient regression

SFE $\quad-$ Supercritical fluid extraction

$\mathrm{SCCO}_{2}-$ Supercritical carbon dioxide

$Y \quad-\quad$ Overall yield (mg of volatile oil $/ \mathrm{mg}$ crude extract)

$Y_{\infty} \quad-\quad$ Overall yield at infinite time

\section{ACKNOWLEDGMENTS}

Authors acknowledge the laboratory of MAPIEM - University of Toulon (France) for providing research facilities to conduct this research.

This paper is dedicated to Prof. L. Piovetti on the occasion of his 80th birthday and in recognition of his efforts in the training of several generations of researchers.

\section{DATA AVAILABILITY STATEMENT}

The authors confirm that the data supporting the findings of this study are available within the article [and/or] its supplementary materials.
FUNDING DETAILS

The authors would like to thank the General Directorate of Scientific Research and Technological Development (DGRSDT - https://www.mesrs.dz/ fr/dgrsdt) for financial support of this work (FNRSDT/2017).

\section{CONFLICT OF INTEREST}

The authors declare that they have no conflict of interest.

\section{References}

1. Kornprobst, J. M., Encyclopedia of marine natural products, Vol. 1, Wiley-Blackwell, Weinheim, 2010, pp 3-56. doi: https://doi.org/10.1002/cbic.201000764

2. Moore, R. E., Chemotaxis and the odor of seaweed, Lloydia 39 (1976) 181.

doi: https://doi.org/10.1016/B978-0-12-505050-0.50014-8

3. Boland, W., Muller, D. G., On the odor of the Mediterranean seaweed Dictyopteris membranacea; New C11 hydrocarbons from marine brown algae-III, Tetrahedron Lett. 28 (1987) 307. doi: https://doi.org/10.1016/S0040-4039(00)95714-9

4. Moore, R. E., Mistysyn, J., Pettus, J. A., (-)-Bis-(3-acetoxyundec-5-enyl) disulphide and S-(-)-3-acetoxyundec-5-enyl thioacetate, possible precursors to undeca-1,3,5-trienes in Dictyopteris, J. Chem. Soc. Chem. Commun. 2113 (1972) 326. doi: https://doi.org/10.1039/C39720000326

5. Schnitzler, I., Boland, W., Hay, M. E., Organic sulfur compounds from Dictyopteris spp. deter feeding by an herbivorous amphipod (Ampithoe longimana) but not by an herbivorous sea urchin (Arbacia punctulata), J. Chem. Ecol. 24 (1998) 1715 doi: https://doi.org/10.1023/A:1020876830580

6. Segawa, M., Yamano, K., Shirahama, H., A germacrane-type sesquiterpene from the brown alga Dictyopteris divaricata, Phytochem. 29 (1990) 973.

doi: https://doi.org/10.1016/0031-9422(90)80058-O

7. Suzuki, M., Kowata, N., Kurosawa, E., Epicubebol and related sesquiterpenoids from the brown alga Dictyopteris divaricata, Bull. Chem. Soc. Jpn. 54 (1981) 2366. doi: https://doi.org/10.1246/bcsj.54.2366

8. Zancan, K. C., Marques, M. O. M., Petenate, A. J., Meireles, M. A. M., Extraction of ginger (Zingiber Officinale Roscoe) oleoresin with $\mathrm{CO}_{2}$ and co-solvents: Study of the antioxidant action of the oil extracts, J. Supercrit. Fluid. 24 (2002) 57. doi: https://doi.org/10.1016/S0896-8446(02)00013-X

9. Bartley, J. P., A new method for the determination of pungent compounds in ginger (Zingiber officinale), J. Sci. Food Agric. 68 (1995) 215. doi: https://doi.org/10.1002/jsfa.2740680213

10. Alfaro, M. J., Belanger, J. M. R., Padilla, F. C., Pare, J. R. $J$., Influence of solvent, matrix dielectric properties, and applied power on the liquid-phase microwave-assisted processes (MAPTM) extraction of ginger (Zingiber officinale), Food. Res. Int. 36 (2003) 499. doi: https://doi.org/10.1016/S0963-9969(02)00198-9 
11. Chester, T. L., Pinkston, J. D., Raynie, D. E., Supercritical fluid chromatography and extraction, Anal. Chem. 66 (1994) 106R. doi: https://doi.org/10.1021/ac00084a006

12. Yeoh, H. S., Chong, G. H., Azahan, N. M., Rahman, R. A., Choong, T. S. Y., Solubility measurement method and mathematical modelling in supercritical fluids, J. Eng. 17 (2013) 68 . doi: https://doi.org/10.4186/ej.2013.17.3.67

13. Rosa, P. T. V., Meireles, M. A. A., Rapid estimation of the manufacturing cost of extracts obtained by supercritical fluid extraction, J. Food. Eng. 67 (2005) 235. doi: https://doi:10.1016/j.jfoodeng.2004.05.064

14. del Valle, J. M., Urrego, F. A., Free solute content and solute-matrix interactions affect apparent solubility and apparent solute content in supercritical $\mathrm{CO}_{2}$ extractions. A hypothesis paper, J. Supercrit. Fluid. 66 (2012) 157. doi: https://doi:10.1016/j.supflu.2011.10.006

15. Sovová, H., Kučera, J., Jež, J., Rate of the vegetable oil extraction with supercritical $\mathrm{CO}_{2}$-II. Extraction of grape oil, Chem. Eng. Sci. 49 (1994) 415. doi: https://doi.org/10.1016/0009-2509(94)87013-6

16. Mota, F. L., Queimada, A. J., Pinho, S. P., Macedo E. A., Aqueous solubility of some natural phenolic compounds, Ind. Eng. Chem. Res. 47 (2008) 5182. doi: https://doi.org/10.1021/ie071452o

17. Hatami, T., Glisic, S. B., Orlovic, A. M., Modelling and optimization of supercritical $\mathrm{CO}_{2}$ extraction of St. John's Wort (Hypericum perforatum L.) using genetic algorithm, J. Supercrit. Fluid. 62 (2012) 102. doi: https://doi:10.1016/j.supflu. 2011.12.001

18. Chrastil, J., Solubility of solids and liquids in supercritical gases, J. Phys. Chem. 86 (1982) 3016. doi: https://doi.org/10.1021/j100212a041

19. del Valle, J. M., Aguilera, J. M., An improved equation for predicting the solubility of vegetable oils in supercritical $\mathrm{CO}_{2}$, Ind. Eng. Chem. Res. 27 (1988) 1551. doi: https://doi.org/10.1021/ie00080a036

20. Santiago, J. M., Teja, A. S., The solubility of solids in supercritical fluids, Fluid. Phase. Equilib. 158 (1999) 501. doi: https://doi.org/10.1016/S0378-3812(99)00154-5

21. Bartle, K. D., Clifford, A. A., Jafar, S. A., Shilstone, G. F., Solubilities of solids and liquids of low volatility in supercritical carbon dioxide, J. Phys. Chem. Refe. Data. 20 (1991) 713 doi: https://doi.org/10.1063/1.555893

22. Adachi, Y., Lu, B. C. Y., Supercritical fluid extraction with carbon dioxide and ethylene, Fluid. Phase. Equilib. 14 (1983) 147 doi: https://doi.org/10.1016/0378-3812(83)80120-4

23. Gordillo, M. D., Blanco, M. A., Molero, A., de la Ossa, A. E. M., Solubility of the antibiotic penicillin Gin supercritical carbon dioxide, J. Supercritical Fluids, 15 (1999) 183. doi: https://doi.org/10.1016/S0896-8446(99)00008-X

24. Zin, M. M., Anucha, C. B., Bánvölgyi, S., Recovery of phytochemicals via electromagnetic irradiation (microwave-assisted-extraction): Betalain and phenolic compounds in perspective, Foods 9 (2020) 918. doi: https://doi.org/10.3390/foods 9070918

25. Alara, O. R., Abdurahman, N. H., Microwave-assisted extraction of phenolics from Hibiscus sabdariffa calyces: Kinetic modelling and process intensification, Ind. Crop. Prod. 137 (2019) 528. doi: https://doi.org/10.1016/j.indcrop.2019.05.053
26. Patil, D. M., Akamanchi, K. G., Microwave assisted process intensification and kinetic modelling: Extraction of camptothecin from Nothapodytes nimmoniana plant, Ind. Crop. Prod. 98 (2017) 60. doi: https://doi.org/10.1016/j.indcrop.2017.01.023

27. Seikova, I., Simeonov, E., Ivanova, E., Protein leaching from tomato seed-experimental kinetics and prediction of effective diffusivity, J. Food. Eng. 61 (2004) 165. doi: https://doi.org/10.1016/S0260-8774(03)00083-9

28. Liu, Y., Shen, L., From Langmuir kinetics to first- and second order rate equations for adsorption, Langmuir $\mathbf{2 4}$ (2008) 11625. doi: https://doi.org/10.1021/la801839b

29. Krishnan, R. Y., Rajan, K. S., Microwave assisted extraction of flavonoids from Terminalia bellerica: Study of kinetics and thermodynamics, Sep. Purif. Technol. 157 (2016) 169. doi: https://doi.org/10.1016/j.seppur.2015.11.035

30. Dong, Z., Gu, F., Xu, F., Wang, $Q$., Comparison of four kinds of extraction techniques and kinetics of microwave-assisted extraction of vanillin from Vanilla planifolia, Food. Chem. 149 (2014) 54. doi: https://doi.org/10.1016/j.foodchem.2013.10.052

31. Tao, Y., Zhang, Z., Sun, D. W., Kinetic modeling of ultrasound-assisted extraction of phenolic compounds from grape marc: Influence of acoustic energy density and temperature, Ultrason. Sonochem. 21 (2014) 1461. doi: https://doi.org/10.1016/j.ultsonch.2014.01.029.

32. Kitanović, S., Milenović, D., Veljković, V. B., Empirical kinetic models for the resinoid extraction from aerial parts of St. John's wort (Hypericum perforatum L.), J. Biochem. Eng. 41 (2008) 1. doi: https://doi.org/10.1016/j.bej.2008.02.010

33. Dalmau, E., Rosselló, C., Eim, V., Ratti, C., Simal, S. Ultrasound-assisted aqueous extraction of biocompounds from orange byproduct: Experimental kinetics and modelling, Antioxidants (Basel, Switzerland) 9 (2020) 352. doi: https://doi.org/10.3390/antiox9040352

34. El Hattab, M., Culioli, G., Piovetti, L., Chitour, S. E., Valls, $R$., Comparison of various extraction methods for identification and determination of volatile metabolites from the brown alga Dictyopteris membranacea, J. Chromatogr. A 1143 (2007) 1 doi: https://doi.org/10.1016/j.chroma.2006.12.057

35. Guiry, M. D., Guiry, G. M., Algae Base, World-wide Electronic Publication, National University of Ireland, 2018, http://www.algaebase.Org/ 2018 (accessed April 2018).

36. Silberfeld, T., Rousseau, F., de Reviers, B., An updated classification of brown algae (Ochrophyta, Phaeophyceae), Cryptogamie, Algologie 35 (2014) 117. doi: http://dx.doi.org/10.7872/crya.v35.iss2.2014.117

37. Davies, N. W., Gas chromatographic retention indices of monoterpenes and sesquiterpenes on methyl silicone and Carbowax 20M phases, J. Chromatogr. 503 (1990) 1. doi: https://doi.org/10.1016/S0021-9673(01)81487-4

38. Joulain, D., König, W. A., The Atlas of Spectral Data of Sequiterpene Hydrocarbons, E. B. Verlag, Hamburg, 1998, pp 661. doi: https://doi.org/10.1021/np990755n

39. Snyder, L. R., Kirkland, J. J., Glajch, J. L., Practical HPLC Method Development, (2 Eds.), J. Wiley \& Sons, New York, 1997, pp 643-683. doi: https://doi.org/10.1002/9781118592014

40. Ferreira, S. R. S., Nikolov, Z. L., Doraiswamy, L. K., Meireles, M. A. A., Petenate, A. J., Supercritical fluid extraction of black pepper (Piper nigrun L.) essential oil, J. Supercrit. Fluids 14 (1999) 235. doi: https://doi.org/10.1016/S0896-8446(98)00092-8 
41. Sovova, H., Apparent solubility of natural products extracted with near-critical carbon dioxide, Am. J. Analyt. Chem. 3 (2012) 958. doi: https://doi.org/10.4236/ajac.2012.312A127

42. Ambrogi, A., Cardarelli, D. A., Eggers, R., Fractional extraction of paprika using supercritical carbon dioxide and on-line determination of carotenoids, J. Food. Sci. 67 (2002) 3236. doi: https://doi.org/10.1111/j.1365-2621.2002.tb09572.x

43. Gomez-Prieto, M. S., Caja, M. M., Santa-Maria, G., Solubility in supercritical carbon dioxide of the predominant carotenes of tomato skin, J. Am. Oil Chem. Soc. 79 (2002) 897. doi: https://doi.org/10.1007/s11746-002-0576-5

44. Povh, N. P., Marques, M. O. M., Meireles, M. A. A., Supercritical $\mathrm{CO}_{2}$ extraction of essential oil and oleo- resin from chamomile (Chamomilla recutita [L.] raus- chert), J. Supercrit. Fluid. 21 (2001) 245. doi: https://doi.org/10.1016/S0896-8446(01)00096-1

45. Prado, J. M., Prado, G. H. C., Meireles, M. A. A., Scale-up study of supercritical fluid extraction process for clove and sugarcane residue, J. Supercrit. Fluid. 56 (2011) 231. doi: https://doi.org/10.1016/j.supflu.2010.10.036

46. Haqqyana, H., Tania, V. F. W., Suyadi, A. M., Kusuma, H. S., Altway, A., Mahfud, M., Kinetic study in the extraction of essential oil from clove (Syzgium aromaticum) stem using microwave hydrodistillation, Mor. J. Chem. 8 (2020) 64. doi: https://doi.org/10.48317/IMIST.PRSM/morjchem-v8i1.19126

47. del Valle, J. M., Jiménez, M., de la Fuente, J. C., Extraction kinetics of pre-pelletized Jalapeño peppers with supercritical $\mathrm{CO}_{2}$, J. Supercrit. Fluid. 25 (2003) 33. doi: https://doi.org/10.1016/S0896-8446(02)00090-6

48. Saldaña, M. D. A., Temelli, F., Guigard, S. E., Tomberli, B., Gray, C. G., Apparent solubility of lycopene and beta-carotene in supercritical $\mathrm{CO}_{2}, \mathrm{CO}_{2}+$ ethanol and $\mathrm{CO}_{2}+$ canola oil using dynamic extraction of tomatoes, J. Food. Eng. 99 (2010) 1 . doi: https://doi.org/10.1016/j.jfoodeng.2010.01.017

49. Sauceau, M., Letourneau, J. J., Freiss, B., Richon, D., Fages, J., Solubility of eflucimibe in supercritical carbon dioxide with or without a co-solvent, J. Supercrit. Fluid, Elsevier. 31(2004) 133. doi: https://doi.org/10.1016/j.supflu.2003.11.004

50. Mitra, S., Wilson, N. K., An empirical method to predict solubility in supercritical fluids, J. Chromatogr. Sci. 29 (1991) 305 . doi: https://doi.org/10.1093/chromsci/29.7.305 